\title{
FONTES ESTABILIZADAS DE NITROGÊNIO COMO ALTERNATIVA PARA AUMENTAR O RENDIMENTO DE GRÃOS E A EFICIÊNCIA DE USO DO NITROGÊNIO PELO MILHO
}

\author{
Murilo Renan Mota ${ }^{(1) *}$, Luis Sangoi ${ }^{(2)}$, Diego Eduardo Schenatto ${ }^{(2)}$, Willian Giordani ${ }^{(2)}$, \\ Cristian Majolo Boniatti ${ }^{(2)}$ e Leonardo Dall'Igna ${ }^{(2)}$
}

(1) Universidade do Estado de Santa Catarina, Programa de Pós-graduação em Ciências do Solo, Lages, Santa Catarina, Brasil.

(2) Universidade do Estado de Santa Catarina, Departamento de Agronomia, Lages, Santa Catarina, Brasil.

* Autor correspondente.

E-mail: mure_mota@hotmail.com

\section{RESUMO}

A utilização de fontes estabilizadas de $\mathrm{N}$, a partir dos mecanismos de inibição da enzima urease e de inibidores da nitrificação do amônio, pode auxiliar na obtenção de maiores tetos produtivos, contribuindo para a sustentabilidade da atividade agrícola. Este trabalho foi conduzido com o objetivo de avaliar o efeito de diferentes fontes e doses de fertilizantes nitrogenados minerais sobre o rendimento de grãos e a eficiência de uso do $\mathrm{N}$ pelo milho. Fez-se o experimento no campo, no município de Lages, SC, onde foi implantado no delineamento de blocos casualizados, dispostos em parcelas subdivididas. Na parcela principal, foram avaliadas quatro doses de $\mathrm{N}$ em cobertura: $0,70,140$ e $280 \mathrm{~kg} \mathrm{ha}^{-1}$, equivalentes a $0,25,50$ e $100 \%$ da dose recomendada para obter $18.000 \mathrm{~kg} \mathrm{ha}^{-1}$ de grãos. Para cada dose, foram testadas, nas subparcelas, quatro fontes de $\mathrm{N}$ mineral: nitrato de amônio, ureia comum, ureia com inibidor da enzima urease e ureia com inibidor da nitrificação do amônio. $O$ experimento foi implantado nos dias 31/10/2011 e 28/10/2012, no sistema de semeadura direta. $O$ híbrido utilizado foi o P30R50H, semeado na densidade de 90.000 plantas ha-1 e espaçamento entrelinhas de $70 \mathrm{~cm}$. As características agronômicas como teor percentual de $\mathbf{N}$ foliar, índice do teor relativo de clorofila e rendimento de grãos aumentaram linearmente com a elevação das doses de $\mathrm{N}$ em cobertura; porém, não foram influenciadas pelas fontes de adubação nitrogenada. A eficiência de uso do $\mathrm{N}$ diminuiu com o incremento das doses de $\mathrm{N}$ em cobertura no primeiro ano de execução do trabalho. Não houve diferenças entre as quatro fontes, quanto à eficiência de uso do N. A utilização da ureia contendo inibidor da enzima urease e da nitrificação de amônio 
não aumentou o rendimento de grãos do milho e nem melhorou a eficiência de uso do $\mathrm{N}$, em relação aos fertilizantes nitrogenados convencionais (ureia comum e nitrato de amônio).

Palavras-chave: Zea mays, fertilizantes, nitrogênio, eficiência agronômica.

\title{
ABSTRACT: STABILIZED NITROGEN SOURCES AS ANALTERNATIVE FOR INCREASING GRAIN YIELD AND NITROGEN USE EFFICIENCY BY MAIZE
}

\begin{abstract}
The use of stabilized $N$ sources, with mechanisms for inhibition of urease enzyme and with ammonium nitrification inhibitors, may help to achieve higher grain yields, contributing to the sustainability of agricultural activity. The aim of this study was to evaluate the effect of different mineral $N$ sources and application rates on maize grain yield and $N$ use efficiency. A field experiment was carried out in Lages, $S C$, Brazil, in a randomized block design in split-plots. Nitrogen was side-dressed in the main plots at four application rates: $0,70,140$, and $280 \mathrm{~kg} \mathrm{ha}{ }^{-1}$, equivalent to $0,25,50$, and $100 \%$ of the rate recommended to achieve a grain yield of $18,000 \mathrm{~kg} \mathrm{ha} \mathrm{h}^{-1}$. For each application rate, four mineral $\mathrm{N}$ sources were tested in the split-plots: ammonium nitrate, common urea, urea with urease inhibitor, and urea with ammonium nitrification inhibitor. The experiment was set up on 10/31/2011 and 10/28/2012 under a no-tillage system. The hybrid P30R50H was sown at a density of 90,000 plants hat and a between-row spacing of $70 \mathrm{~cm}$. The agronomic traits of percentage of leaf $N$ content, leaf chlorophyll content, and grain yield increased linearly with the increase in the $N$ application rate, but they were not affected by the sources of $N$. Nitrogen use efficiency decreased with the increase in the $N$ application rate in the first year of the study. There were no differences among the four sources in regard to $N$ use efficiency in either year. The use of urea containing urease enzyme inhibitor and ammonium nitrification inhibitor did not increase maize grain yield nor improve the crop efficiency in $N$ use compared to conventional $N$ fertilizers (common urea and ammonium nitrate).
\end{abstract}

Keywords: Zea mays L., fertilizers, nitrogen, agronomic efficiency.

\section{INTRODUÇÃO}

$\mathrm{O} \mathrm{N}$ é o nutriente que proporciona os maiores efeitos nos componentes do rendimento e na produtividade do milho, influenciando diversas características do crescimento e desenvolvimento (Cobucci, 1991). Assim, uma das principais ferramentas no manejo da lavoura para obter altas produtividades é o uso de elevadas doses de fertilizantes nitrogenados.

$\mathrm{O} N$ é o nutriente de manejo e recomendação mais complexos, em virtude da multiplicidade de reações químicas e biológicas a que está sujeito e de sua grande dependência das condições edafoclimáticas para absorção pela planta (Cantarella e Duarte, 2004). Apenas uma parte do N mineral aplicado é absorvido pelas plantas. O restante é perdido do sistema solo-planta-atmosfera por processos de lixiviação, volatilização, erosão e desnitrificação, tendo ainda uma fração que permanece no solo na forma orgânica (Vargas, 2010).

A natureza complexa das transformações do $\mathrm{N}$ no solo pode provocar assincronia entre a disponibilidade do nutriente no solo e a demanda pelas culturas. Dessa forma, a aplicação de N via fertilizantes minerais proporciona eficiência global em torno de $50 \%$, sendo o restante perdido ou imobilizado temporariamente na biomassa microbiana do solo (Bayer e Fontoura, 2006).

A baixa eficiência de recuperação do $\mathrm{N}$ de fertilizantes nitrogenados aplicados às culturas tem sido atribuída principalmente a perdas por volatilização de amônia $\left(\mathrm{NH}_{3}\right)$, oriunda de fontes amoniacais de $\mathrm{N}$ e lixiviação de nitrato $\left(\mathrm{NO}_{3}^{-}\right)$, implicando em maior custo com fertilizantes e mão de obra (Rogeri, 2010).

A lixiviação consiste no movimento vertical de íons ou de moléculas no perfil do solo para profundidades abaixo daquelas exploradas pelas raízes. Ela é a reação mais importante que ocorre com o $\mathrm{N}$ em áreas com alta precipitação pluvial, principalmente nos solos de países de clima tropical (Ernani, 2008).

Levando em consideração o potencial de perdas do $\mathrm{N}$ por lixiviação de $\mathrm{NO}_{3}^{-}$em solos agrícolas, Bayer e Fontoura (2006) recomendaram que a maior parte da aplicação do fertilizante nitrogenado seja feita em cobertura, num período imediatamente anterior ao de maior demanda das culturas pelo $\mathrm{N}$.

A fração do $\mathrm{N}$ amoniacal $\left(\mathrm{NH}_{4}^{+}\right)$está sujeita a perdas por volatilização da amônia, que é influenciada pela umidade do solo no momento da aplicação do fertilizante, pelo tipo de solo, pela fonte de $\mathrm{N}$ empregada e pelo manejo do adubo nitrogenado (Bayer e Fontoura, 2006). 
A ureia é o fertilizante nitrogenado mais usado no Brasil por apresentar boa combinação entre eficiência agronômica e preço em relação aos demais adubos nitrogenados (Ernani, 2008). No entanto, o uso de ureia como fonte de $\mathrm{N}$ pode ocasionar elevadas perdas do nutriente, principalmente se aplicada em cobertura sem incorporação. A permanência dos resíduos culturais na superfície do solo no sistema de plantio direto pode promover uma barreira para o contato do fertilizante com o solo, promovendo perdas de $\mathrm{N}$ por volatilização de amônia (Fontoura e Bayer, 2006).

A Associação Americana de Agentes para o Controle de Nutrientes de Plantas (AAPFCO) define como "Fertilizantes Estabilizados" aqueles que contêm aditivos para aumentar o tempo de disponibilidade no solo, como inibidores de nitrificação, inibidores de urease ou outros aditivos (Cantarella, 2007). A utilização de fertilizantes estabilizados com adição de polímeros inibidores da atividade da enzima urease e, ou, da nitrificação do amônio, à ureia, pode elevar a eficiência da adubação nitrogenada, promovendo maiores rendimentos de grãos à cultura do milho.

Inibidores de urease são compostos adicionados à ureia com a finalidade de diminuir a atividade da enzima urease, com impacto negativo sobre a hidrólise da ureia, diminuindo as perdas por volatilização de amônia e aumentando o aproveitamento de $\mathrm{N}$ pelas plantas. A ureia com inibidor de urease retarda os picos de volatilização de $\mathrm{NH}_{3}$, em relação à ureia convencional (Tasca, 2009).

Os inibidores de nitrificação são compostos adicionados aos fertilizantes amídicos ou amoniacais com o objetivo de retardar a atividade das bactérias nitrificadoras, que oxidam o amônio a nitrato. $\mathrm{O}$ revestimento de ureia por polímeros contendo inibidores pode promover maior estabilidade do fertilizante no solo. Miyazawa e Tiski (2011) observaram elevação do teor de $\mathrm{N}-\mathrm{NH}_{4}^{+}$no solo quando se utilizou a ureia revestida com inibidores da nitrificação do amônio, em comparação ao solo adubado com ureia sem revestimento. Dessa forma, se pode obter eficiente redução das perdas de $\mathrm{N}$ por lixiviação.

A utilização de fontes estabilizadas de $\mathrm{N}$ com inibidor de urease e de nitrificação do amônio pode ser uma estratégia para aumentar a eficiência de uso do $\mathrm{N}$ pelo milho. Isso pode permitir a redução das doses de $\mathrm{N}$ aplicadas em cobertura e dos custos de produção, sem comprometimento da produtividade. Além disso, essas fontes podem elevar os tetos produtivos da cultura, a partir das doses empregadas atualmente. Considerando tais hipóteses, conduziu-se este trabalho com o objetivo de avaliar o efeito de diferentes fontes e doses de $\mathrm{N}$ em cobertura sobre o rendimento de grãos e a eficiência de uso do $\mathrm{N}$ pelo milho.

\section{MATERIAL E MÉTODOS}

O experimento foi conduzido no campo, durante os anos agrícolas de 2011/12 e 2012/13, em Lages, no Planalto Sul de Santa Catarina. As coordenadas geográficas do local são $27^{\circ} 50^{\prime} 35^{\prime \prime} \mathrm{S}, 50^{\circ} 02^{\prime} 45^{\prime \prime} \mathrm{W}$ e 849 m de altitude. De acordo com a classificação de Köppen, o clima da região é do tipo Cfb, mesotérmico, com verões brandos e precipitações pluviais bem distribuídas.

O solo da área experimental é classificado como Nitossolo Vermelho distrófico típico (Embrapa, 2006). A camada arável, 0-20 cm do solo, apresentava em setembro de 2011 as seguintes características: $420 \mathrm{~g} \mathrm{~kg}^{-1}$ de argila; $50,0 \mathrm{~g} \mathrm{~kg}^{-1}$ de matéria orgânica; $\mathrm{pH}\left(\mathrm{H}_{2} \mathrm{O}\right) 5,6$; índice SMP de 5,$8 ; 5 \mathrm{mg} \mathrm{dm}^{-3}$ de $\mathrm{P} ; 0,50 \mathrm{cmol}_{\mathrm{c}} \mathrm{kg}^{-1}$ de $\mathrm{K}^{+}$; 6,0 $\mathrm{cmol}_{\mathrm{c}} \mathrm{kg}^{-1}$ de $\mathrm{Ca}^{2+} ; 2,8 \mathrm{cmol}_{\mathrm{c}} \mathrm{kg}^{-1}$ de $\mathrm{Mg}^{2+}$; $0,3 \mathrm{cmol}_{\mathrm{c}} \mathrm{kg}^{-1}$ de $\mathrm{Al}^{3+}$; e $15,3 \mathrm{cmol}_{\mathrm{c}} \mathrm{kg}^{-1}$ de CTC.

$\mathrm{O}$ delineamento experimental utilizado foi de blocos casualizados dispostos em parcelas subdivididas, com quatro repetições por tratamento. Nas parcelas principais, foram testadas quatro doses de $\mathrm{N}$ mineral em cobertura: 0, 70, 140 e 280 $\mathrm{kg} \mathrm{ha}^{-1}$ de N, correspondentes a $0,25,50$ e $100 \%$ da dose recomendada pela Comissão de Química e Fertilidade do Solo - RS/SC (CQFSRS/SC, 2004) para alcançar uma produtividade de $18.000 \mathrm{~kg} \mathrm{ha}^{-1}$. Nas subparcelas, foram avaliadas quatro fontes de N: nitrato de amônio, ureia convencional, ureia com inibidor da urease (Super N) e ureia com inibidor da nitrificação do amônio (Potenza). A cobertura nitrogenada foi feita em dose única nos dias 02/12/2011 e 05/12/2012, quando as plantas apresentavam seis folhas totalmente expandidas, estádio V6 da escala de Ritchie et al. (1993). Cada subparcela foi composta por quatro linhas de $6 \mathrm{~m}$ de comprimento, espaçadas $0,7 \mathrm{~m}$ entre si, tendo como área útil $8,4 \mathrm{~m}^{2}$ provenientes das duas linhas centrais.

No mês junho de 2011 e 2012, procedeu-se à semeadura de um consórcio de aveia-preta (Avena strigosa) mais ervilhaca (Vicia sativa). Essa cobertura de inverno foi dessecada mediante a aplicação do herbicida glifosato no final do mês de setembro de cada ano agrícola.

Utilizou-se o sistema de semeadura direta do milho, em área sob plantio direto consolidado desde 1999, sobre a cobertura morta de aveia-preta e ervilhaca. A adubação de manutenção foi determinada seguindo as recomendações da CQFSRS/SC (2004), com o objetivo de produzir $18.000 \mathrm{~kg} \mathrm{ha}^{-1}$ de grãos, que foi fornecida no dia da semeadura, nas seguintes doses: $295 \mathrm{~kg} \mathrm{ha}^{-1} \mathrm{de}_{2} \mathrm{O}_{5}$, $170 \mathrm{~kg} \mathrm{ha}^{-1} \mathrm{de}_{2} \mathrm{O}$ e $30 \mathrm{~kg} \mathrm{ha}^{-1}$ de N. Os fertilizantes foram distribuídos superficialmente próximos às linhas de semeadura. 
A semeadura foi realizada em 31 de outubro de 2011 e 28 de outubro de 2012 , com semeadoras manuais, depositando-se três sementes por cova. O híbrido utilizado foi o P30R50H. A densidade almejada foi de 90.000 plantas ha ${ }^{-1} \mathrm{e}$ o espaçamento entrelinhas de $0,7 \mathrm{~m}$.

Quando as plantas se encontravam no estádio V3 da escala de Richie et al. (1993), efetuou-se o desbaste para ajustar a população para 90.000 plantas ha ${ }^{-1}$.

Quando as plantas alcançaram o estádio R1 (espigamento) da escala de Richie et al. (1993), fizeram-se a avaliação do índice do teor relativo de clorofila (TRC) e a do teor de $\mathrm{N}$ foliar. Para as duas determinações, utilizou-se a folha-índice localizada no mesmo nó do colmo onde estava inserida a espiga superior da planta. A estimativa do TRC foi feita com o clorofilômetro SPAD 502 Plus. Para definir o teor percentual de $\mathrm{N}$ foliar, procedeu-se à coleta do terço médio da folha-índice de cada uma das plantas amostradas. As amostras foram secas em estufa, moídas; posteriormente, fez-se a digestão do tecido com ácido sulfúrico, seguido por destilação por arraste de vapores e titulação, conforme método descrito por Tedesco et al. (1995).

A colheita do experimento foi feita quando todas as folhas estavam senescidas e a umidade dos grãos estava abaixo de $25 \%$. As espigas foram colhidas manualmente, considerando todas as plantas da área útil da subparcela. $\mathrm{O}$ rendimento de grãos foi determinado a partir da massa de grãos e expresso na umidade padrão de $130 \mathrm{~g} \mathrm{~kg}^{-1}$. A massa de 1.000 grãos foi discriminada a partir da separação de uma amostra de 400 grãos, convertida para $130 \mathrm{~g} \mathrm{~kg}^{-1} \mathrm{e}$ multiplicada por 2,5. O número de grãos por espiga foi obtido por meio de relações entre a massa de 1.000 grãos, a massa total de grãos e o número de espigas colhidas na área útil de cada unidade experimental. $\mathrm{O}$ número de espigas por planta foi obtido dividindo-se o número de espigas colhidas pelo número de plantas existentes na área útil das unidades experimentais.

A eficiência agronômica de uso do $\mathrm{N}$ foi determinada segundo Fageria e Baligar (2005), em que $\mathrm{EA}=(\mathrm{PGcf}-\mathrm{PGsf}) /(\mathrm{QNa})$, expressa em kg kg${ }^{-1}$, em que EA é a eficiência agronômica; PGcf, a produção de grãos com fertilizante nitrogenado; PGsf, a produção de grãos sem fertilizante nitrogenado; e $\mathrm{QNa}$, a quantidade em $\mathrm{kg}$ de $\mathrm{N}$ aplicado.

Nos dois anos de condução do experimento, foi realizada irrigação complementar durante o florescimento da cultura e enchimento de grãos, sempre que detectada a ocorrência de déficit hídrico. $\mathrm{O}$ monitoramento foi feito a partir da instalação de pluviômetros na área experimental. Não se efetuou a irrigação da área experimental no mês de dezembro, a fim de evitar a incorporação do adubo nitrogenado aplicado em cobertura ao solo. $\mathrm{Na}$ figura 1, apresentam-se os dados de precipitação pluvial registrados na área experimental.

Foram coletados dados meteorológicos de temperatura (Quadro 1) na Empresa de Pesquisa Agropecuária e Extensão Rural de Santa Catarina S.A. (EPAGRI) e no Centro de Informações de Recursos Ambientais e de Hidrometeorologia de Santa Catarina (CIRAM), entre os meses de outubro e abril de cada ano agrícola, coincidindo com a estação de crescimento do milho. A Estação Agrometeorológica de Lages, SC, localiza-se a $20 \mathrm{~km}$ da área experimental.

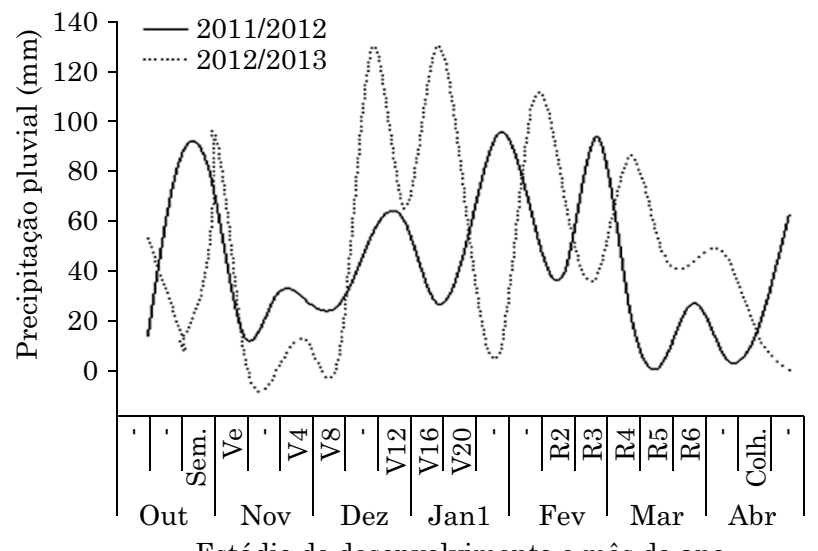

Figura 1. Precipitação pluvial para a cultura do milho nos anos agrícolas 2011/2012 e 2012/2013.

Quadro 1. Temperatura média mensal do ar nos anos agrícolas de 2011/12 e 2012/2013 e temperatura média entre outubro e abril de 1976 a 2010, em Lages, SC

\begin{tabular}{|c|c|c|c|c|c|c|c|c|}
\hline \multirow{2}{*}{ Período } & \multicolumn{7}{|c|}{ Temperatura média mensal } & \multirow{2}{*}{ Média } \\
\hline & Out & Nov & Dez & Jan & Fev & Mar & Abr & \\
\hline & \multicolumn{8}{|c|}{${ }^{\circ} \mathrm{C}$} \\
\hline Média entre 1976/2010 & 16,2 & 17,7 & 19,7 & 19,8 & 20,0 & 19,7 & 15,9 & 18,5 \\
\hline Ano agrícola de 2011/12 & 16,7 & 17,3 & 18,8 & 20,2 & 21,9 & 19,3 & 16,5 & 18,7 \\
\hline Ano agrícola de 2012/13 & 16,6 & 18,4 & 21,4 & 18,9 & 19,5 & 17,4 & 15,3 & 18,2 \\
\hline
\end{tabular}

Fonte: Empresa de Pesquisa Agropecuária e Extensão Rural de Santa Catarina S.A. - EPAGRI; Centro de Informações de Recursos Ambientais e de Hidrometeorologia de Santa Catarina - CIRAM; e Estação Agrometeorológica de Lages, SC. 
Os dados obtidos foram avaliados estatisticamente pela análise de variância. Quando alcançada significância estatística no teste $\mathrm{F}$, as médias dos fatores qualitativos (fontes de $\mathrm{N}$ mineral em cobertura) foram comparadas entre si pelo teste de Tukey. O efeito das doses crescentes de $\mathrm{N}$ foi avaliado por regressão polinomial, testando-se os modelos polinomial e quadrático, e selecionando-se aquele que melhor se ajustou aos dados obtidos. Tanto os testes de médias quanto as análises de regressão foram utilizados a $5 \%$ de significância.

\section{RESULTADOS E DISCUSSÃO}

A análise estatística dos dados referentes a teor percentual de $\mathrm{N}$, teor relativo de clorofila (TRC) na folha-índice, rendimento de grãos e eficiência agronômica (EA) de uso do $\mathrm{N}$ demonstrou que as fontes estabilizadas de $\mathrm{N}$ testadas no trabalho não foram superiores à ureia e ao nitrato de amônio. No quadro 2, apresentam-se os dados da análise de variância para o primeiro e segundo ano agrícola, respectivamente. Tampouco foi constatada interação significativa entre fontes $\times$ doses de $\mathrm{N}$ em cobertura.

O teor percentual de $\mathrm{N}$ e o teor relativo de clorofila (TRC) na folha-índice do milho foram influenciados significativamente pela dose de N. Eles aumentaram linearmente com o incremento na quantidade de $\mathrm{N}$ aplicada em cobertura (Figura 2).

Fernandes e Buzetti (2005), assim como Aratani (2006) e Gomes et al. (2007), também observaram elevação linear no teor de $\mathrm{N}$ das folhas em resposta ao incremento de doses de $\mathrm{N}$ no milho. No entanto, Melo et al. (2011) e Souza et al. (2011), avaliando a resposta do incremento de doses de $\mathrm{N}$, combinadas com distintas fontes e formas de aplicação de adubos nitrogenados, obtiveram elevação quadrática do $\mathrm{N}$ foliar com a elevação das doses. Jordão et al. (2010) também observou incremento linear do TRC nas folhas de milho em resposta à elevação das doses

Quadro 2. Análise de variância para o teor percentual de nitrogênio foliar, índice do teor relativo de clorofila (TRC), ambos na folha índice do milho, rendimento de grãos e eficiência agronômica (EA) de uso do nitrogênio pelo milho - safras 2011/2012 e 2012/2013

\begin{tabular}{|c|c|c|c|c|c|}
\hline \multirow[t]{2}{*}{ FV } & \multirow[t]{2}{*}{ GL } & \multicolumn{4}{|c|}{ QM } \\
\hline & & TRC & Teor de $\mathbf{N}$ foliar & Rendimento de grãos & EA \\
\hline & & & & $2011 / 2012$ & \\
\hline Blocos & 3 & $132,8^{*}$ & $0,1^{\text {ns }}$ & $5.186 .739,1^{\mathrm{ns}}$ & $1.671,8^{\text {ns }}$ \\
\hline Trat-a (Ta) ${ }^{(1)}$ & 3 & $714,8^{-(3)}$ & $1,9^{--}$ & 209.201.332,9- & $132.875,3^{--}$ \\
\hline Resíduo (a) & 9 & 17,5 & 0,1 & $3.791 .068,3$ & 650,6 \\
\hline Parcelas & 15 & & & & \\
\hline CV a (\%) & & 9,6 & 11,0 & 15,7 & 42,9 \\
\hline Trat-b (Tb) ${ }^{(2)}$ & 3 & $7,5^{\mathrm{ns}}$ & $0,1^{\text {ns }}$ & $830.660,1^{\mathrm{ns}}$ & $524,2^{\text {ns }}$ \\
\hline Int. $\mathrm{Ta} \times \mathrm{Tb}$ & 9 & $5,2^{\mathrm{ns}}$ & $0,1^{\mathrm{ns}}$ & $513.754,3^{\text {ns }}$ & $511,9^{\text {ns }}$ \\
\hline Resíduo (b) & 36 & 4,5 & 0,1 & $720.568,4$ & 334,6 \\
\hline Total & 63 & & & & \\
\hline \multirow[t]{2}{*}{ CV b (\%) } & & 4,8 & 12,8 & 6,9 & 19,6 \\
\hline & & & & $2012 / 2013$ & \\
\hline Blocos & 3 & $9,3^{\text {ns }}$ & $0,1^{\text {ns }}$ & $20.299,4^{*}$ & $1.138,4^{\mathrm{ns}}$ \\
\hline Trat-a (Ta) & 3 & $598,6^{-}$ & 5,3-- & $139.859 .142,8^{--}$ & $424,5^{-}$ \\
\hline Resíduo (a) & 9 & 14,5 & 0,1 & $15.09 .320,9$ & 214,2 \\
\hline Parcelas & 15 & & & & \\
\hline CV a (\%) & & 8,4 & 14,4 & 10,9 & 42,9 \\
\hline Trat-b (Tb) & 3 & $12,8^{\mathrm{ns}}$ & $0,01^{\mathrm{ns}}$ & $143.164,9^{\text {ns }}$ & $60,5^{\mathrm{ns}}$ \\
\hline Int. $\mathrm{Ta} \times \mathrm{Tb}$ & 9 & $7,3^{\text {ns }}$ & $0,01^{\text {ns }}$ & $658.430,6^{\mathrm{ns}}$ & $40,7^{\text {ns }}$ \\
\hline Resíduo (b) & 36 & 7,3 & 0,10 & $466.668,1$ & 33,2 \\
\hline Total & 63 & & & & \\
\hline CV b (\%) & & 5,9 & 10,5 & 6,1 & 16,9 \\
\hline
\end{tabular}

(1) (Ta): doses de N mineral em cobertura; ${ }^{(2)}(\mathrm{Tb})$ : fontes de $\mathrm{N}$ mineral: ureia comum, nitrato de amônio, ureia com inibidor da urease e ureia com inibidor da nitrificação; ${ }^{(3)}$-- os tratamentos são quantitativos, teste $\mathrm{F}$ não se aplica. ${ }^{\text {ns }}$ não diferem significativamente pelo teste $\mathrm{F}(\mathrm{p}<0,05)$; * significativo pelo teste $\mathrm{F}$ a $5 \%$. 

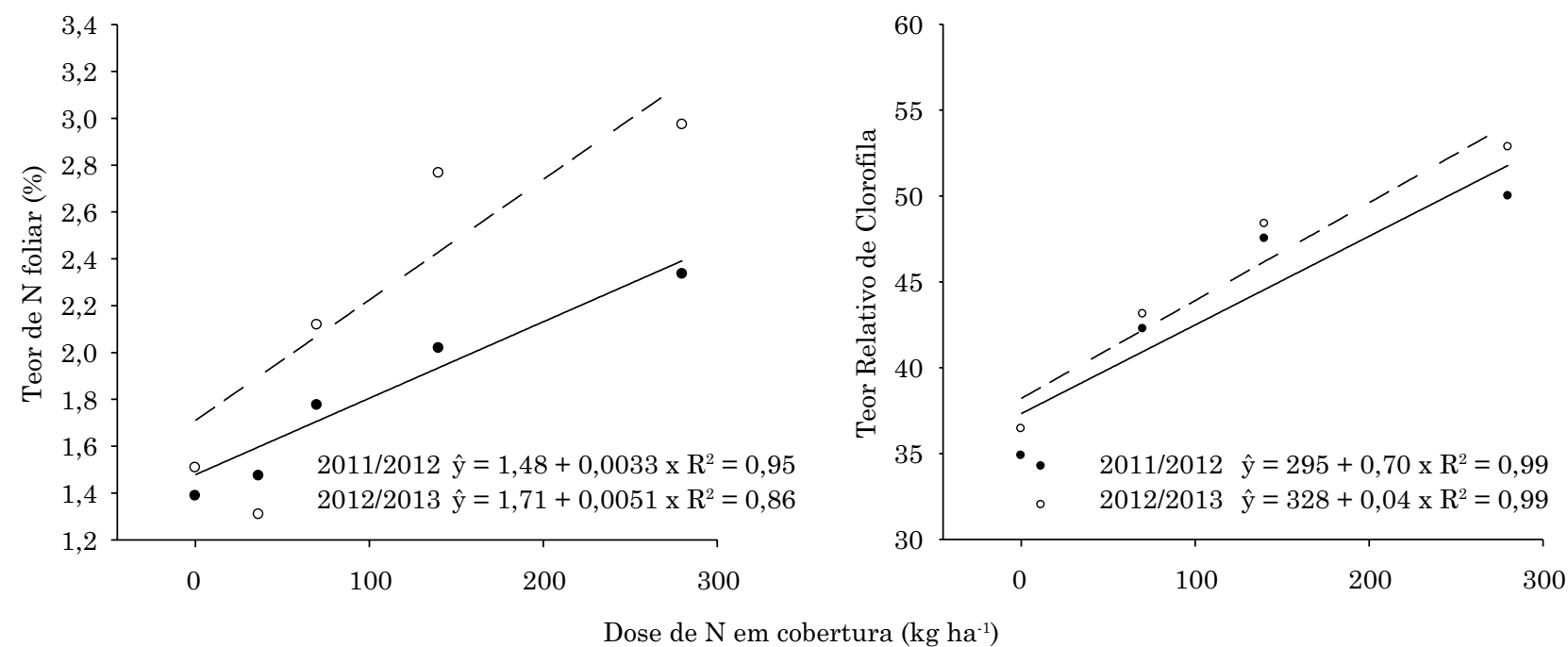

Figura 2. Teor de $\mathbf{N}$ foliar e Teor Relativo de Clorofila (TRC) na folha-índice do milho em função da aplicação de quatro doses e quatro fontes de $\mathrm{N}$ em cobertura - 2011/12 e 2012/2013.

de $\mathrm{N}$ aplicadas. Esses autores, assim como Netto (2012), constataram alta correlação entre o teor de $\mathrm{N}$ foliar e a leitura do índice TRC foliar medida pelo clorofilômetro. Eles atribuíram essa correlação ao fato de que mais de $50 \%$ do $\mathrm{N}$ presente nas folhas faz parte das moléculas de clorofila.

O TRC vem sendo considerado melhor indicador do nível de $\mathrm{N}$ do que o teor desse nutriente na folha, sendo pouco sensível ao consumo de luxo de N (Rambo et al., 2004). Em razão da sua alta relação com o rendimento de grãos, a determinação do TRC tem sido usada para predizer a necessidade de adubação nitrogenada em cobertura em várias culturas.

De acordo com Argenta et al. (2003), os valores de leitura no clorofilômetro podem ser utilizados eficientemente para monitorar o nível de $\mathrm{N}$ em milho. Apesar da limitação de não quantificar a dose a ser aplicada, a leitura do TRC permite fazer um diagnóstico da lavoura em poucos minutos. Os autores citaram o índice de leitura de 58 no clorofilômetro durante o espigamento como nível adequado de $\mathrm{N}$, independentemente do híbrido usado, quando se almeja elevado potencial de rendimento de grãos. Esse valor está acima do encontrado neste experimento, para os dois anos agrícolas.

Nos dois anos agrícolas, não houve efeito significativo da fonte de $\mathrm{N}$ sobre o teor percentual de $\mathrm{N}$ na folha e sobre o TRC na folha-índice, independentemente das doses de $\mathrm{N}$ aplicadas em cobertura (Quadro 3). Essas duas variáveis são indicativas do estado nutricional nitrogenado da planta na floração. A ausência de efeito da fonte sobre ambas indica que as quantidades de $\mathrm{N}$ absorvidas pela planta até o espigamento foram semelhantes para as quatro fontes testadas no trabalho. $\mathrm{O}$ comportamento do teor percentual de $\mathrm{N}$ da folha-índice detectado neste trabalho difere do reportado por Soratto et al. (2010). Esses autores observaram maior teor de $\mathrm{N}$ foliar com a aplicação de sulfonitrato de amônio com inibidor da nitrificação DMPP do que quando se utilizou sulfato de amônio e ureia.

Nos dois anos agrícolas, o rendimento de grãos apresentou um incremento linear em resposta à elevação das doses de $\mathrm{N}$ aplicadas em cobertura, independentemente da fonte empregada (Figura 3). Em 2011/12, o rendimento de grãos evoluiu de 8.000 $\mathrm{kg} \mathrm{ha}^{-1}$ na dose zero para $16.600 \mathrm{~kg} \mathrm{ha}^{-1}$ com aplicação de $280 \mathrm{~kg}$ de $\mathrm{N}$ em cobertura. Em 2012/2013, os valores de rendimento observados foram inferiores aos do ano anterior, variando de $7.200 \mathrm{~kg} \mathrm{ha}^{-1}$ na dose zero em cobertura até $15.000 \mathrm{~kg} \mathrm{ha}^{-1}$, na

Quadro 3. Teor percentual de nitrogênio e índice do teor relativo de clorofila (TRC) na folha índice do milho, em razão da aplicação de quatro doses e quatro fontes de nitrogênio em cobertura 2011/2012 e 2012/2013

\begin{tabular}{|c|c|c|c|c|}
\hline \multirow[t]{2}{*}{ Fonte de $\mathrm{N}^{(1)}$} & \multicolumn{2}{|c|}{ Teor de $\mathrm{N}$ foliar } & \multicolumn{2}{|c|}{ Índice do TRC } \\
\hline & $1^{\circ}$ ano & $2^{\circ}$ ano & $1^{\circ}$ ano & $2^{\circ}$ ano \\
\hline & \multicolumn{2}{|c|}{$\%$} & & \\
\hline N.A. & 1,9 & 2,4 & 43 & 46 \\
\hline U.C. & 1,7 & 2,3 & 43 & 46 \\
\hline U.U. & 2,0 & 2,4 & 44 & 44 \\
\hline U.N. & 1,9 & 2,3 & 44 & 44 \\
\hline Teste F & $2.0^{\mathrm{ns}}$ & $0.1^{\mathrm{ns}}$ & $1.7^{\mathrm{ns}}$ & $1.7^{\mathrm{ns}}$ \\
\hline CV (\%) & 12,8 & 10,5 & 4,8 & 6,0 \\
\hline
\end{tabular}

(1) N.A.: Nitrato de Amônio; U.C.: Ureia Comum; U.U.: Ureia com inibidor da Urease; e U.N.: Ureia com Inibidor da Nitrificação. ns: não diferem significativamente pelo teste $\mathrm{F}(\mathrm{p}<0,05)$. 
dose máxima. A diferença de rendimento de grãos registrada entre os dois anos provavelmente se deve à condição climática mais adversa apresentada no segundo ano, quando se constatou, no início da estação de crescimento, um período sem chuvas, concentrado no mês de novembro e primeiro decêndio de dezembro (Figura 1).

Nos dois anos agrícolas, não houve efeito significativo das fontes de $\mathrm{N}$ testadas no trabalho sobre o rendimento de grãos, independentemente da dose aplicada em cobertura (Quadro 4). Soratto et al. (2011) avaliaram diferentes fontes e doses de $\mathrm{N}$ na cultura do milho e também não obtiveram respostas de produtividade para fontes, porém relataram elevação quadrática do rendimento com elevação das doses. Na mesma linha, Souza e Soratto (2006) obtiveram resposta linear do rendimento com aumento das doses de $\mathrm{N}$.

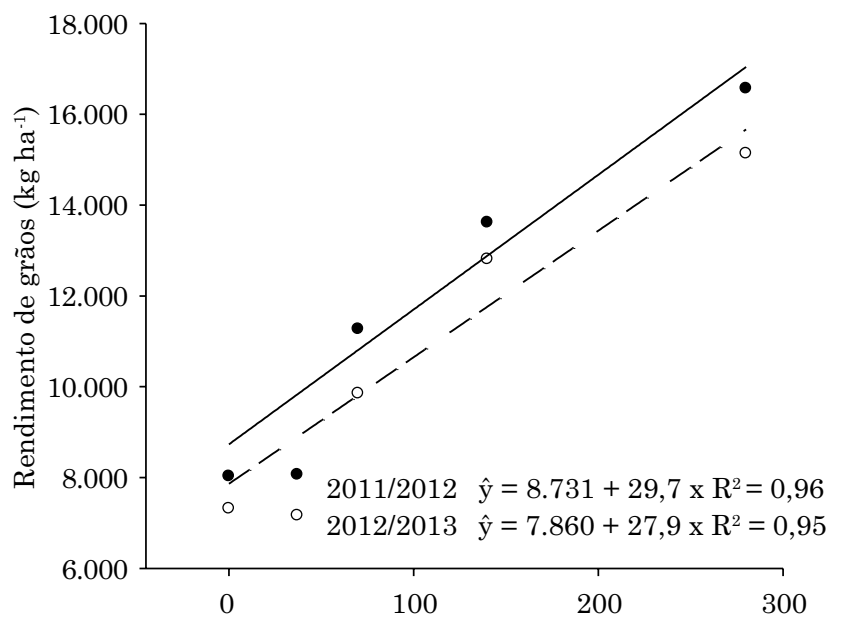

A massa de 1.000 grãos e o número de grãos/ espiga foram influenciados pela dose de $\mathrm{N}$ aplicada em cobertura. Nos dois anos agrícolas, esses componentes do rendimento aumentaram linearmente com o incremento na quantidade de $\mathrm{N}$ aplicada à cultura (Figuras 3 e 4). Isso provavelmente ocorreu porque o incremento na dose de $\mathrm{N}$ aumentou o teor de clorofila das folhas (Figura 2) e, consequentemente, as taxas fotossintéticas da cultura, permitindo-lhe diferenciar maior número de espiguetas e produzir mais grãos por espiga. Além disso, doses mais altas de $\mathrm{N}$ mantêm as folhas fisiologicamente ativas por mais tempo, prolongando a duração do período de enchimento de grãos e favorecendo a produção de grãos mais pesados (Silva et al., 2005).

O número de espigas por planta não foi influenciado pela progressão das doses de $\mathrm{N}$ no primeiro ano de condução do experimento e

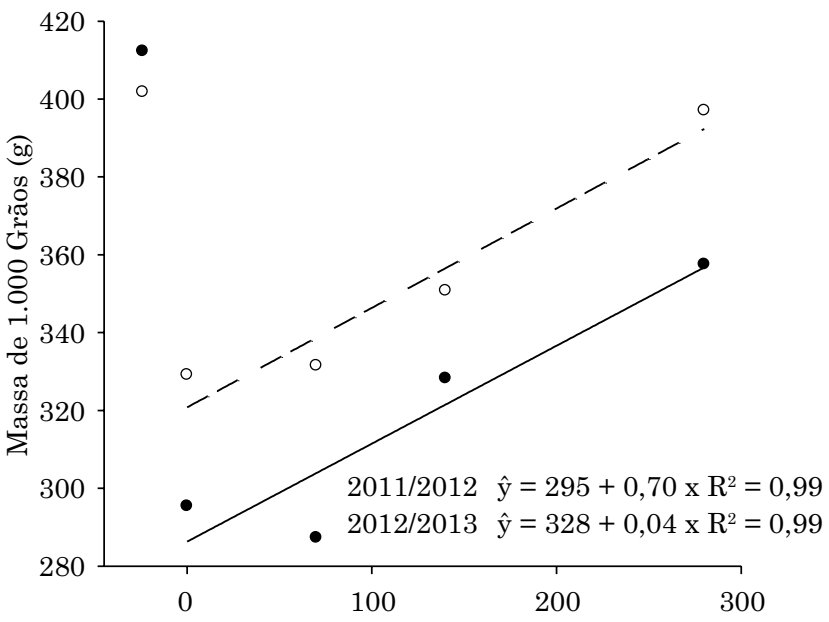

Dose de $\mathrm{N}$ em cobertura $\left(\mathrm{kg} \mathrm{ha}^{-1}\right)$

Figura 3. Rendimento de grãos e massa de 1.000 grãos do milho em função da aplicação de quatro doses e quatro fontes de $\mathrm{N}$ em cobertura - 2011/12 e 2012/2013.

Quadro 4. Rendimento de grãos e componentes do rendimento, em razão da aplicação de quatro doses e quatro fontes de nitrogênio em cobertura - 2011/2012 e 2012/2013

\begin{tabular}{|c|c|c|c|c|c|c|c|c|}
\hline \multirow[t]{2}{*}{ Fonte de $\mathrm{N}^{(1)}$} & \multicolumn{2}{|c|}{ Rendimento de grãos } & \multicolumn{2}{|c|}{ Massa de 1.000 grãos } & \multicolumn{2}{|c|}{ Grãos por espiga } & \multicolumn{2}{|c|}{ Grãos por $\mathbf{m}^{2}$} \\
\hline & $1^{\circ}$ ano & $2^{\circ}$ ano & $1^{\circ}$ ano & $2^{\circ}$ ano & $1^{\circ}$ ano & $2^{\circ}$ ano & $1^{\circ}$ ano & $2^{\circ}$ ano \\
\hline & \multicolumn{2}{|c|}{$\mathrm{kg} \mathrm{ha}^{-1}$} & \multicolumn{2}{|c|}{$\mathrm{g}$} & \multicolumn{4}{|c|}{$\mathrm{n}^{\mathrm{o}}$} \\
\hline N.A. & 12.500 & 11.400 & $324 \mathrm{a}$ & 354 & $431 \mathrm{ab}$ & 357 & 3.824 & 3.150 \\
\hline U.C. & 12.300 & 11.300 & $321 \mathrm{ab}$ & 351 & $427 \mathrm{~b}$ & 356 & 3.789 & 3.200 \\
\hline U.U. & 12.500 & 11.300 & $308 \mathrm{~b}$ & 350 & $459 \mathrm{a}$ & 355 & 4.030 & 3.200 \\
\hline U.N. & 12.100 & 11.100 & $315 \mathrm{ab}$ & 354 & $437 \mathrm{ab}$ & 354 & 3.804 & 3.100 \\
\hline Teste F & $1.1^{\mathrm{ns}}$ & $0.3^{\mathrm{ns}}$ & $2.9079^{*}$ & $0.2307^{\mathrm{ns}}$ & $3.4428^{*}$ & $0,1^{\mathrm{ns}}$ & $2.8^{\mathrm{ns}}$ & $0.5^{\mathrm{ns}}$ \\
\hline CV (\%) & 6,9 & 6,1 & 5,2 & 4,8 & 7,0 & 6,4 & 7,0 & 7,0 \\
\hline
\end{tabular}

(1) N.A.: Nitrato de Amônio; U.C.: Ureia Comum; U.U.: Ureia com inibidor da Urease; e U.N.: Ureia com Inibidor da Nitrificação. ns: não diferem significativamente pelo teste $\mathrm{F}(\mathrm{p}<0,05) ;{ }^{*}$ significativo pelo teste $\mathrm{F}$ a $5 \%$. Letras minúsculas comparam as fontes entre si, na coluna, pelo teste de Tukey $(\mathrm{p}<0,05)$. 


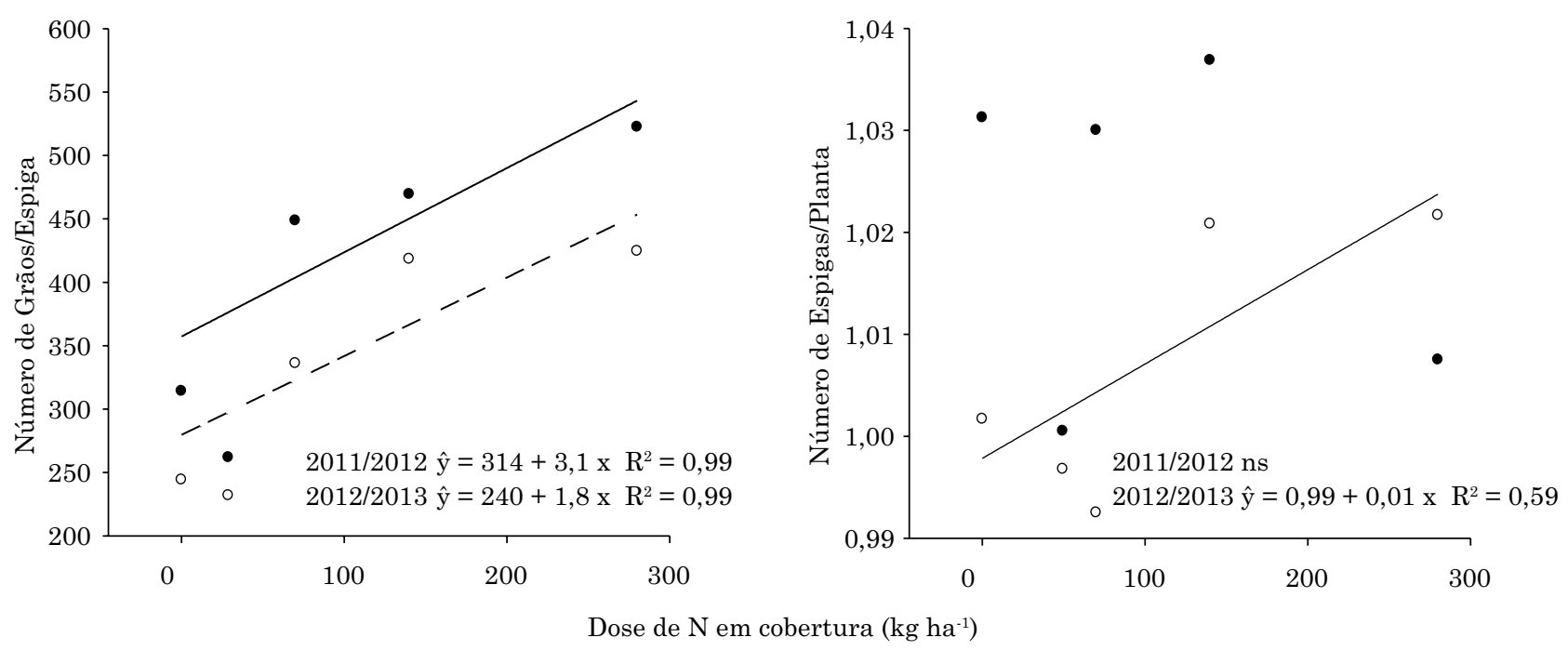

Figura 4. Número de grãos/espiga e número de espigas/planta do milho em função da aplicação de quatro doses e quatro fontes de $\mathrm{N}$ em cobertura - 2011/12 e 2012/2013.

apresentou elevação linear no segundo ano (Figura 4b). Soratto et al. (2010) também obtiveram elevação linear no número de espigas/planta, grãos/espiga e na massa de 1.000 grãos, como reposta à elevação das doses de $\mathrm{N}$ em cobertura no milho.

No primeiro ano agrícola, a massa de 1.000 grãos e o número de grãos/espiga foram influenciados significativamente pela fonte de $\mathrm{N}$ empregada. A ureia com inibidor da urease apresentou menor massa de 1.000 grãos do que o nitrato de amônio, porém não diferiu das demais fontes testadas (Quadro 5). Contudo, ela foi também a fonte que apresentou o maior valor numérico de grãos/espiga, entre as quatro fontes. Esse efeito compensatório entre os componentes do rendimento pode explicar a ausência de diferença de fontes para o rendimento de grãos.

No primeiro ano agrícola, a eficiência agronômica de uso do N (EA) foi influenciada pela dose de N. Ela reduziu numericamente com a elevação da quantidade de $\mathrm{N}$ aplicada em cobertura, sendo o menor valor registrado na dose máxima de $280 \mathrm{~kg} \mathrm{ha}^{-1}$ (Quadro 5). As demais doses não diferiram estatisticamente entre si pelo teste Tukey a $5 \%$ de significância. Esses dados concordam com obtidos por Farinelli e Lemos (2010). Júnior et al. (2011), testando a eficiência de fontes estabilizadas de adubação nitrogenada na redução de perdas de $\mathrm{N}$ na forma de nitrato, também relataram a redução na EA com o aumento da dose aplicada, em sintonia com a lei dos rendimentos decrescentes. No segundo ano, a EA não foi influenciada pela progressão de doses de $\mathrm{N}$ em cobertura. A EA não foi influenciada pela fonte de $\mathrm{N}$ utilizada no trabalho nos dois anos agrícolas.

A ausência de resposta ao fator fontes de adubação nitrogenada (Quadros 2, 3, 4 e 5), pode ser explicada pelas condições ambientais desfavoráveis
Quadro 5. Eficiência Agronômica (EA) de uso do nitrogênio pelo milho, em razão da aplicação de quatro doses e quatro fontes de nitrogênio em cobertura - 2011/2012 e 2012/2013

Dose de N Eficiência Agronômica de uso do N pelo milho

\begin{tabular}{|c|c|c|}
\hline & $1^{\circ}$ ano & ${ }^{\circ}$ ano \\
\hline $\mathrm{kg} \mathrm{ha}^{-1}$ & \multicolumn{2}{|c|}{$\mathrm{kg} \mathrm{kg}^{-1}$} \\
\hline 70 & $49 \mathrm{a}$ & 36 \\
\hline 140 & $40 \mathrm{ab}$ & 39 \\
\hline 280 & $30 \mathrm{~b}$ & 27 \\
\hline Teste F & $4.8^{*}$ & $1.9^{\mathrm{ns}}$ \\
\hline CV (\%) & 42,9 & 42,9 \\
\hline \multicolumn{3}{|c|}{ Fontes de $\mathrm{N}^{(1)}$} \\
\hline N.A. & 38 & 36 \\
\hline U.C. & 42 & 35 \\
\hline U.U. & 41 & 35 \\
\hline U.N. & 39 & 30 \\
\hline Teste F & $0.6^{\mathrm{ns}}$ & $1.8^{\mathrm{ns}}$ \\
\hline CV (\%) & 19,6 & 16,9 \\
\hline
\end{tabular}

(1) N.A.: Nitrato de Amônio; U.C.: Ureia Comum; U.U.: Ureia com inibidor da Urease; e U.N.: Ureia com Inibidor da Nitrificação. ns: não diferem significativamente pelo teste $\mathrm{F}(\mathrm{p}<0,05)$; * significativo pelo teste $\mathrm{F}$ a $5 \%$. Letras minúsculas comparam as fontes entre si, na coluna, pelo teste de Tukey $(p<0,05)$.

para perdas acentuadas de $\mathrm{N}$ por lixiviação do $\mathrm{NO}_{3}^{-}$ e volatilização da amônia.

A intensidade do processo de lixiviação é inversamente proporcional ao número de sítios de adsorção. Por isso, para uma mesma quantidade de adubo aplicado, a lixiviação será diretamente proporcional ao teor de areia do solo e inversamente proporcional aos teores de argila e de matéria orgânica (Ernani, 2008). 
O Nitossolo Vermelho, onde se implantou o trabalho, é um solo de textura argilosa, sendo pouco propício a perdas de $\mathrm{N}$ por lixiviação de $\mathrm{NO}_{3}^{-}$. Além disso, anos que apresentaram precipitação pluvial bem distribuída, como demonstraram os dados meteorológicos para a região de implantação nos dois anos do experimento (Figura 1), foram menos favoráveis à perda de $\mathrm{N}$ por lixiviação de $\mathrm{NO}_{3}^{-}$(Ernani, 2008). Coincidentemente, nos dois anos agrícolas, a primeira precipitação de grande volume ocorreu apenas no $12^{\circ}$ dia após a adubação nitrogenada em cobertura. Assim, é possível que boa parte do $\mathrm{N}$ aplicado já tivesse sido absorvida pela cultura, considerando a grande demanda por $\mathrm{N}$ apresentada pelas plantas de milho, que se encontravam com seis folhas expandidas, no momento da adubação em cobertura.

Um fator que, também, pode interferir na magnitude da lixiviação é o pH do solo. Em condições onde o pH é baixo e o fertilizante nitrogenado é aplicado sobre a superfície do solo, ocorre retardamento da lixiviação de $\mathrm{NO}_{3}^{-}$, facilitando absorção de $\mathrm{N}$ pelas plantas. $\mathrm{O} \mathrm{pH}$ relativamente baixo $\left[\mathrm{pH}\left(\mathrm{H}_{2} \mathrm{O}\right)\right.$ de 5,6], o alto teor de matéria orgânica $\left(50,0 \mathrm{~g} \mathrm{~kg}^{-1}\right)$ apresentado pelo solo da área experimental, associado ao modo de aplicação do fertilizante (em superfície), assim como a textura fina do solo cultivado, além da condição de precipitação pluvial bem distribuída na região de implantação do experimento, formaram um conjunto de fatores desfavorável às perdas de $\mathrm{N}$ por lixiviação de $\mathrm{NO}_{3}^{-}$.

As perdas de $\mathrm{N}$ por volatilização de amônia são influenciadas por fatores de solo (CTC, $\mathrm{pH}$ e textura) e do ambiente (temperatura atmosférica, precipitação e umidade relativa do ar). Em solos alcalinos, a concentração de $\mathrm{OH}^{-}$é elevada, favorecendo perdas de $\mathrm{NH}_{3}$ por volatilização (Bissani et al., 2008). O pH do solo da área experimental (pH 5,6) não apresentou condições ideais para a amonificação, pois nessas condições o amônio não encontrou grandes concentrações de hidroxilas, o que determinaria a formação de amônia.

Sangoi et al. (2003) avaliaram a volatilização de amônia em função da aplicação da ureia em superfície de dois solos: arenoso (Neossolo Quartzarênico), com baixa CTC, e argiloso (Nitossolo Vermelho), com alta CTC. Os autores relataram que enquanto no solo arenoso $54 \%$ do $\mathrm{N}$ adicionado volatilizaram, no solo argiloso, de mesma classificação do solo encontrado na área experimental deste trabalho, apenas $14 \%$ do $\mathrm{N}$ aplicado volatilizaram. Esse dado reforçou a hipótese de que a textura argilosa e a CTC elevada do Nitossolo Vermelho, utilizadas neste trabalho, reduziu as perdas de $\mathrm{N}$ por volatilização, mitigando as vantagens potenciais da ureia com inibidor de urease sobre as demais fontes.

A temperatura atmosférica elevada favorece as perdas de $\mathrm{N}$ por volatilização da amônia. Tasca (2009), avaliando as perdas de N por volatilização de amônia para duas fontes, ureia comum e ureia com inibidor da urease, verificou grande aumento da volatilização de amônia com o aumento da temperatura de 18 para $35^{\circ} \mathrm{C}$. Neste trabalho, a temperatura de $35{ }^{\circ} \mathrm{C}$ volatilizou maior quantidade de amônia do que a de $18{ }^{\circ} \mathrm{C}$ para ambas as fontes de $\mathrm{N}$ avaliadas; quanto mais elevada a temperatura do ambiente, maior a perda de $\mathrm{N}$ por volatilização de amônia. Nos anos agrícolas 2011/12 e 2012/13, a análise dos dados meteorológicos da região onde foi implantado o experimento evidenciou para o mês de dezembro, quando se procedeu a adubação nitrogenada em cobertura, temperaturas médias amenas que variaram de 18,8 a $21,4{ }^{\circ} \mathrm{C}$ (Quadro 1 ). Isso indicou que as temperaturas médias diárias foram pouco propícias para a volatilização da amônia.

A umidade do solo no momento da aplicação do fertilizante nitrogenado interfere sobre a atividade da urease e a volatilização da amônia. Tasca (2009) verificou que as perdas de $\mathrm{N}$ por volatilização foram reduzidas pela condição de baixa umidade do solo por ocasião da adubação de cobertura. $\mathrm{O}$ solo seco (0\% umidade) promoveu menores perdas de $\mathrm{N}$ do que as demais umidades avaliadas. Em solo seco, a atividade da urease é menor e a ureia pode permanecer estável. Desse modo, a aplicação da ureia em solo seco é preferível à sua adição em solo excessivamente úmido (Mariano et al., 2011).

Nos dois anos de condução do trabalho, a cobertura nitrogenada foi realizada há mais de cinco dias da última precipitação, quando a superfície do solo apresentava baixa umidade. Em 2011/2012, a ocorrência de baixos volumes de precipitações no decorrer do $6^{\circ}(2 \mathrm{~mm}), 7^{\circ}(4 \mathrm{~mm})$ e $8^{\circ}$ dias $(21 \mathrm{~mm})$, após a aplicação da adubação em cobertura (Figura 1), pode ter promovido a incorporação do $\mathrm{N}$ ao solo, reduzindo as possibilidades de perdas de $\mathrm{N}$ por volatilização da amônia. Essa hipótese ganha força considerando que os picos de volatilização ocorrem a partir do $3^{\circ}$ dia, após a aplicação da ureia em cobertura, sendo as perdas máximas do $4^{\circ}$ ao $7^{\circ}$ dias (Tasca, 2009).

Se por um lado as temperaturas médias diárias da primeira quinzena do mês de dezembro de 2011 não foram determinantes para promover a volatilização da amônia, mesmo após um período observado de cinco dias sem chuvas, as precipitações, quando ocorreram a partir do $6^{\circ}$ ao $8^{\circ}$ dia, ao mesmo tempo em que foram insuficientes para promover perdas de $\mathrm{N}$ por lixiviação de $\mathrm{NO}_{3}^{-}$em profundidade no perfil do solo, foram importantes para promover a incorporação do adubo nitrogenado ao solo, num período de intensa demanda de $\mathrm{N}$ pelo milho.

No segundo ano agrícola, ocorreram precipitações de 0,$1 ; 17,5 ; 2,1$ e $8,8 \mathrm{~mm}$, no $2^{\circ}, 5^{\circ}, 6^{\circ}$ e $7^{\circ}$ dia, após a realização da adubação nitrogenada de cobertura, respectivamente. Esses volumes de chuva contribuíram para incorporar o $\mathrm{N}$ proveniente das diferentes fontes de adubação nitrogenada ao 
solo, aumentando a disponibilidade do nutriente à cultura, justamente num momento de grande demanda de $\mathrm{N}$ pelo milho. Entretanto, a precipitação ocorrida não foi suficiente para promover lixiviação de $\mathrm{NO}_{3}^{-}$no perfil do solo.

O conjunto de fatores edáficos e climáticos pode explicar o desempenho semelhante apresentado para as diferentes fontes de $\mathrm{N}$, principalmente se forem considerados os rendimentos de grãos de 16.565 e $15.030 \mathrm{~kg} \mathrm{ha}^{-1}$, obtidos quando se utilizaram $100 \%$ da dose recomendada, em 2011/12 e 2012/13, respectivamente. Essas produtividades demonstraram o excelente desempenho apresentado para todas as quatro fontes nitrogenadas testadas.

A adoção de pré-culturas em sistemas de rotação de culturas resulta numa série de benefícios à qualidade do solo e ao rendimento das culturas, incluindo o alto potencial de fornecimento de $\mathrm{N}$ para a cultura do milho (Bayer e Fontoura, 2006). Tais fatores podem ter contribuído para a ausência de diferença entre as fontes para rendimento de grãos, especialmente em se tratando de área de lavoura sob plantio direto consolidado, com alto teor de matéria orgânica e com sucessão de culturas, com aveia-preta e ervilhaca no inverno.

A testemunha, sem aplicação de $\mathrm{N}$ mineral, apresentou produtividade de grãos superior a $7 \mathrm{t} \mathrm{ha}^{-1}$, evidenciando elevada disponibilidade de $\mathrm{N}$ no solo. Bayer e Fontoura (2006) atestaram o bom potencial do uso de pré-culturas no rendimento do milho em um solo com alto teor de MO. Os autores obtiveram rendimentos de $5 \mathrm{t} \mathrm{ha}^{-1} \mathrm{em}$ sucessão à aveia-preta $\mathrm{e}$ 10 t ha $^{-1}$ de grãos de milho em sucessão à ervilhaca, com dose zero de $\mathrm{N}$ mineral, respectivamente.

Os dados de rendimento de grãos corroboraram a argumentação de que as perdas de $\mathrm{N}$ por volatilização de $\mathrm{NH}_{3}$ e por lixiviação de $\mathrm{NO}_{3}^{-}$, embora possam ter ocorrido em intensidades diferentes entre as quatro fontes testadas, não foram captadas pelas plantas. Assim, o milho teve quantidades semelhantes de $\mathrm{N}$ para sua nutrição, independentemente da fonte utilizada. A ausência de efeito significativo das fontes de $\mathrm{N}$ sobre o teor percentual de $\mathrm{N}$ foliar e sobre o índice do teor relativo de clorofila no espigamento (Quadro 2) corroborou essa informação, indicando que o nível nutricional das plantas quanto ao $\mathrm{N}$ era semelhante no início do enchimento de grãos. Essa característica acabou se confirmando após a colheita no rendimento de grãos e na eficiência de uso do $\mathrm{N}$.

\section{CONCLUSÃO}

Em solos de textura argilosa, cultivados em sistema de plantio direto consolidado sob condição de temperaturas amenas e precipitações pluviais bem distribuídas, o uso de fontes estabilizadas com polímeros inibidores da enzima urease e da nitrificação do amônio não aumenta o rendimento de grãos e a eficiência agronômica de uso do N, comparativamente à ureia comum e ao nitrato de amônio, independentemente da dose de $\mathrm{N}$ aplicada em cobertura.

\section{REFERÊNCIAS}

Aratani RG. Adubação nitrogenada de cobertura na cultura do milho irrigado, em sistema plantio direto. R Ci Eletr Agron. 2006;9:1-10

Argenta G, Silva PRF, Fosthofer EL, Strieder ML, Suhre E, Teichmann LL. Adubação nitrogenada em milho pelo monitoramento do nível de nitrogênio na planta por meio do clorofilômetro. R Bras Ci Solo. 2003;27:109-19.

Bayer C, Fontoura SMV. Dinâmica do nitrogênio no solo, préculturas e o manejo da adubação nitrogenada na cultura do milho em plantio direto. In: Fontoura SMV, Bayer C, editores. Manejo e fertilidade de solos em plantio direto. Guarapuava: Fundação Agrária de Pesquisa Agropecuária; 2006.

Bissani CA, Gianello C, Camargo FAO, Tedesco MJ. Fertilidade dos solos e manejo da adubação de culturas. $2^{a}$ ed. Porto Alegre: Metrópole; 2008.

Cantarella H. Fontes de nitrogênio. In: Novais RF, Alvarez V VH, Barros NF, Fontes RLF, Cantarutti RB, Neves JCL, editores. Fertilidade do solo. Viçosa, MG: Sociedade Brasileira de Ciências do Solo: 2007. p.416-49.

Cantarella H, Duarte AP. Manejo da fertilidade do solo para a cultura do milho. In: Galvão JCC, Miranda GV, editores. Tecnologias de produção do milho. Viçosa, MG: Universidade Federal de Viçosa; 2004. p.139-82.

Cobucci T. Efeitos de doses e épocas de aplicação em cobertura do adubo nitrogenado no consórcio milho-feijão [tese]. Viçosa, MG: Universidade Federal de Viçosa; 1991.

Comissão de Química e Fertilidade do Solo - CQFSRS/SC. Manual de adubação e calagem para os estados do Rio Grande do Sul e Santa Catarina. $10^{\mathrm{a}}$ ed. Porto Alegre: Sociedade Brasileira de Ciência do Solo; 2004.

Empresa Brasileira de Pesquisa Agropecuária - Embrapa. Sistema brasileiro de classificação de solos. $2^{\mathrm{a}}$ ed. Brasília, DF: Centro Nacional de Pesquisa de Solos; 2006

Ernani PR. Química do solo e disponibilidade de nutrientes. Lages: O Autor; 200.

Fageria NK, Baligar VC. Enhancing nitrogen use efficiency in crop plants. Adv Agron. 2005;88:97-185.

Farinelli R, Lemos LB. Produtividade e eficiência agronômica do milho em função da adubação nitrogenada e manejos do solo. $\mathrm{R}$ Bras Milho Sorgo. 2010;9:135-46.

Fernandes FCS, Buzetti S. Efeito de níveis de nitrogênio na produtividade de seis cultivares de milho (Zea mays L.). R Ci Eletr Agron. 2005;7:195-204.

Gomes RF, Silva AG, Assis LR, Pires RP. Efeito de doses e da época de aplicação de nitrogênio nos caracteres agronômicos da cultura do milho sob plantio direto. R Bras Ci Solo. 2007;31:931-8. 
Jordão LT, Lima FF, Lima RS, Moretti PAE, Pereira HV, Muniz AS, Oliveira MCN. Teor relativo de clorofila em folhas de milho inoculado com Azospirillum braziliense sob diferentes doses de nitrogênio e manejo com braquiária. In: Anais da $29^{\text {a }}$ Reunião Brasileira de Fertilidade do Solo e Nutrição de Plantas [CDROM]; 2010; 17-21 set 2010; Guarapari. Guarapari: Sociedade Brasileira de Ciência do Solo; 2010.

Júnior LAZ, Dalchiavon F, Zagotto RG, Santos C. Eficiência agronômica do revestimento da uréia com polímero aplicada em cobertura na cultura do milho. In: Anais do $32^{\circ}$. Congresso Brasileiro de Ciência do Solo; 2011; 20-25 jul 2011; Uberlândia. Uberlândia: Sociedade Brasileira de Ciência do Solo; 2011.

Mariano E, Costa HT, Corrales RAF. Ureia: Novas tecnologias para fertilizantes nitrogenados. Piracicaba: Universidade de São Paulo; 2011.

Melo FB, Corá JE, Cardoso MJ. Fertilização nitrogenada, densidade de plantas e rendimento de milho cultivado no sistema plantio direto. R Ci Agron. 2011;42:27-31.

Miyazawa M, Tiski I. Teores de $\mathrm{N}^{-\mathrm{NH}_{4}}{ }^{+}$no solo em função de fontes nitrogenadas: Uréia e uréia revestida por policote. In: Anais do $32^{\circ}$. Congresso Brasileiro de Ciência do Solo [CD-ROM]; 2011; 20-25 jul 2011; Uberlândia. Uberlândia: Sociedade Brasileira de Ciência do Solo; 2011.

Netto APC. Efeito de diferentes fontes de nitrogênio no teor de clorofila em diferentes híbridos de milho cultivados em segunda safra. In: Anais do $29^{\circ}$ Congresso Nacional de Milho e Sorgo [CD-ROM]; 2012; 26-30 ago 2012; Águas de Lindoia. Águas de Lindoia: Empresa Brasileira de Pesquisa Agropecuária; 2012.

Rambo L, Silva PRF, Argenta G, Sangoi L. Parâmetros de planta para aprimorar o manejo da adubação nitrogenada de cobertura em milho. Ci Rural. 2004;34:1637-45.

Ritchie SW, Benson GO, Lupkes SJ. How a corn plant develops. Ames: Iowa State University of Science and Technology; 1993. (Special report, 4).
Rogeri DA. Suprimento e perdas de nitrogênio no solo decorrentes da adição de cama de aves [dissertação]. Lages: Universidade do Estado de Santa Catarina; 2010.

Sangoi L, Ernani PR, Lech VA, Rampazzo C. Volatilização de $\mathrm{N}-\mathrm{NH}_{3}$ em decorrência da forma de aplicação de uréia, manejo de resíduos e tipo de solo, em laboratório. Ci Rural. 2003;33:687-92.

Silva PRF, Strieder ML, Coser RPS, Rambo L, Sangoi L, Argenta G, Forsthofer EL, Silva AA. Grain yield and kernel protein content increases of maize hybrids with late nitrogen side-dresses. Sci Agric. 2005;62:487-92.

Soratto RP, Silva AH, Cardoso SM, Mendonça SG. Doses e fontes alternativas de nitrogênio no milho sob plantio direto em solo arenoso. Ci Agrotec. 2011;35:62-70.

Soratto RP, Pereira M, Costa TAM, Lampert VN. Fontes alternativas e doses de nitrogênio no milho safrinha em sucessão à soja. R Ci Agron. 2010;41:511-8.

Souza EFC, Soratto RP. Efeitos de fontes de nitrogênio em cobertura, no milho safrinha em plantio direto. R Bras Milho Sorgo. 2006;5:395-405.

Souza JA, Buzetti S, Teixeira Filho MCM, Andreotti M, Sá ME, Arf O. Adubação nitrogenada na cultura do milho safrinha irrigado em plantio direto. Bragantia. 2011;70:447-54.

Tasca FA. Volatilização de amônia a partir da aplicação de duas fontes de nitrogênio, em laboratório [dissertação]. Lages: Universidade do Estado de Santa Catarina; 2009.

Tedesco MJ, Giancelo C, Bissani CA, Bohnen H, Volkweiss SJ. Análise de solo, plantas e outros materiais. $2^{\mathrm{a}}$ ed. Porto Alegre: Universidade Federal do Rio Grande do Sul, 1995. (Boletim técnico, 5).

Vargas VP. Manejo da adubação nitrogenada na recuperação de estresses em milho [dissertação]. Lages: Universidade do Estado de Santa Catarina; 2010. 